\title{
The Description of Pancreatic Cancer Death in Inner Mongolia 2008-2014
}

\author{
Xiaoyan Zhang1*, Ying Shi ${ }^{2}$, Changqing Sun ${ }^{3 *}$, Lei Guo ${ }^{4}$, Hairong Zhang5, Zhiyun Zhou1, \\ Dan Wang5, Jing Yan', Linlin Dong1, Qingxia Wang5, Yueling Hu', Juan Sun ${ }^{5 \#}$ \\ ${ }^{1}$ Inner Mongolia Medical University Affiliated Hospital, Hohhot, China \\ ${ }^{2}$ Chifeng Municipal Hospital, Chifeng, China \\ ${ }^{3}$ Huhhot First Hospital, Hohhot, China \\ ${ }^{4}$ Baotou Cancer Hospital, Baotou, China \\ ${ }^{5}$ Inner Mongolia Medical University, Hohhot, China \\ Email: "sj6840@163.com
}

How to cite this paper: Zhang, X.Y., Shi, Y., Sun, C.Q., Guo, L., Zhang, H.R., Zhou, Z.Y., Wang, D., Yan, J., Dong, L.L., Wang, Q.X., Hu, Y.L. and Sun, J. (2017) The Description of Pancreatic Cancer Death in Inner Mongolia 2008-2014. Open Journal of Epidemiology, 7, 131-138.

https://doi.org/10.4236/ojepi.2017.72012

Received: March 24, 2017

Accepted: April 23, 2017

Published: April 28, 2017

Copyright (C) 2017 by authors and Scientific Research Publishing Inc. This work is licensed under the Creative Commons Attribution International License (CC BY 4.0).

http://creativecommons.org/licenses/by/4.0/

\begin{abstract}
Objective: The study aimed to assess the characteristics of pancreatic cancer deaths and the relationship between socio-demographic status and mortality risk of pancreatic cancer in Inner Mongolia. Method: We obtained our data for 2008-2014 from the Death Registry System of Inner Mongolia. We calculated the mortality rate, potential years of life lost (PYLL) and average years of life lost (AYLL) for men and women. We collected socio-demographic characteristics including education level, ethnicity, region, and occupation. Logistic regression models were employed to analyze risk factors of pancreatic cancer. Results: The average mortality rate of pancreatic cancer was 4.42/100,000 in Inner Mongolia during 2008 to 2014. Mortality rate in men was higher in all age groups compared with those in women. The highest mortality rate was 1.3 times than the lowest mortality rate for men and 1.6 times for women during seven years. Average AYLL in women were more than 3.4 years compared with that in men. PYLLR in women was fluctuated from 0.41 to 0.63 per thousand during 2008 to 2014. In eastern region, no occupation and high education level had a higher risk of pancreatic cancer. Conclusion: In Inner Mongolia, the mortality rate associated with pancreatic cancer was higher in men compared with in women. More than 65 years old groups had high death risk for pancreatic cancer. Average years of life lost for women were significantly higher than that for men. We should pay more attention to the older men.
\end{abstract}

\section{Keywords}

Pancreatic Cancer, Multiple Factor Analysis, PYLL, AYLL 


\section{Introduction}

Pancreatic cancer has been considered an "orphan cancer" and would be of little concern except for its exceptionally high mortality rate [1]. Globally, pancreatic cancer is placed in the eighth for mortality rate among any type of cancer [2]. In the United States of America (USA), pancreatic cancer is the fourth most frequent cause of cancer death after lung, breast, prostate, and colorectal cancer [3]. In Japan, it is the fifth most common cause of cancer death [4]. At the beginning of the $21^{\text {st }}$ century, the estimated number of pancreatic cancers death throughout the world was 110,000, with an estimated mortality rate of 98\% [5]. Up to now, we have found that the mortality rate of pancreatic cancer had an increasing trend. In Japan, the mortality rate had been increasing in 1968-2002 [6]. The mortality rate was rising in China during the period 2003-2009 [7]. The death cases of pancreatic cancer in China were beyond the number of cases in the United States in 2010 [5]. GLOBOCAN 2012 estimates that cases in China account for $19.45 \%$ of all newly diagnosed pancreatic cancer and $19.27 \%$ of all deaths from pancreatic cancer worldwide [8]. We didn't find the epidemiological study of pancreatic cancer death in Inner Mongolia till now, the paper analyzes the potential years of life lost, average years of life lost and influencing factors of pancreatic cancer mortality in Inner Mongolia in 2008-2014.

\section{Materials and Methods}

\subsection{Data Collection}

The study examined data was obtained by the Chinese Ministry of Health and the Center for Disease Control (CDC) of Inner Mongolia. Data on deaths were collected through the Death Registry System (DRS) of 20 monitoring points. DRS uses a multistage cluster probability sampling strategy with stratification according to eastern, central and western of China, the local gross domestic product (GDP) and proportion of rural dwellers, the total population of local areas [9]. The study divided these eight monitoring points into two regions in 2008-2012: the Eastern region including Yakeshi City, Kailu County, Bairin Youqi, Sonid Youqi, the midwest region including Ejin Horo Qi, Muslims District, Tumd Youqi and Linhe district. From 2013 to 2014, cause of death monitoring points are up to 20 , new increasing districts from the eastern region including Keshiketeny country, naiman country, Arong Banner, Manzhouli city, Horqin Right Wing Middle Banner, Xi Ujimqin Banner. New increasing districts from the midwest region include Haibowan District, Dongsheng District, Chayouqianqi, Alxazuoqi, Wuchuan County, Qingshan District.

Codes from the $10^{\text {th }}$ version of International Classification of Diseases (ICD10) [9] were used to define the death cause of pancreatic cancer (codes C25). The annual midyear population figures in 2008-2014 were obtained from the CDC of Inner Mongolia to calculate age-specific mortality rate, gender-specific mortality rate and annual mortality of each region per 100,000 people [10].

We conducted a cross-sectional observational study for pancreatic cancer 
death in Inner Mongolia 2008-2014. We collected cases characteristics including education level, occupation, ethnicity and region to assess the demographic characteristics of pancreatic cancer related mortality rate. Education level is divided into low (illiterate, primary school), high (middle school, junior high school, technical school, college, university, university above). The illiterate was defined the person who can't read and literacy. Primary school was defined a person who accepts formal education of initial stage, length of schooling is six years [11].

\subsection{Statistical Analyses}

Mortality rate, potential years of life lost (PYLL), rate of PYLL (PYLLR and average years of life lost (AYLL) were calculated for men and women. PYLL: PYLL $=\Sigma\left(\mathrm{ai}{ }^{\star} \mathrm{di}\right)=\Sigma(\mathrm{L}-\mathrm{Xi}-0.5) \times \mathrm{di}$, where ai $=$ loss of life-years for a certain age group, and $\mathrm{di}=$ the number of deaths in that particular age group [9], $\mathrm{L}=$ upper age level limit, $\mathrm{Xi}=$ Median number for each age group. $\mathrm{PYLLR}=(\mathrm{PYLL} / \mathrm{n}) \times$ $1000 \%$, where $\mathrm{n}$ is the total population at risk. AYLL $=\mathrm{PYLL} / \mathrm{di}$, that is the average difference value between the life expectancy and the actual age at death [12]. SPSS 22.0 statistical software (IBM SPSS, Inc., Chicago, IL, USA) were used for data management and analyses. Logistic regression analysis was used to assess risk factors, with a significance level of 0.05 .

\section{Result}

The average mortality rate was 4.42/100,000 in Inner Mongolia during the years of 2008 to 2014. The total mortality rate of pancreatic cancer between 3.97/ 100,000 to $5.23 / 100,000$ fluctuations during the seven years. The highest mortality rate was 5.92/100,000 in 2011 for men and 4.49/100,000 in 2011 for women. The lowest mortality rate was $4.49 / 100,000$ in 2013 for men and 2.73/100,000 in 2010 for women. The highest mortality rate was 1.3 times compared with the lowest mortality rate for men and 1.6 times for women during the years of 2008 to 2014 .

Figure 1 shows age-specific mortality of pancreatic cancer in Inner Mongolia from 2008 to 2014. Regardless of men or women, the mortality rate of pancreatic cancer increased with aging, then reached the top at the highest age group (over 85 years old). Mortality rate in men were higher in all age groups compared with those in women.

Figure 2 shows gender-specific mortality rate of pancreatic cancer in Inner Mongolia in 2008 and 2014. The mortality rate of pancreatic cancer in 2014 had an obviously increased compared with that in 2008. Regardless of in 2008 or 2014 , the mortality rate of pancreatic cancer in men was higher than that in women. The mortality rate of pancreatic cancer was 1.7 times and 1.3 times respectively for women and men in 2014 than that in 2008.

Table 1 shows AYLL, PYLL and PYLLR for pancreatic cancer in Inner Mongolia from 2008 to 2014. We observed a total PYLL of 7435.76 years for men and 6005.37 years for women during the years of 2008 to 2014. Average AYLL in women were more than 3.4 years compared with that in men. PYLLR in men 


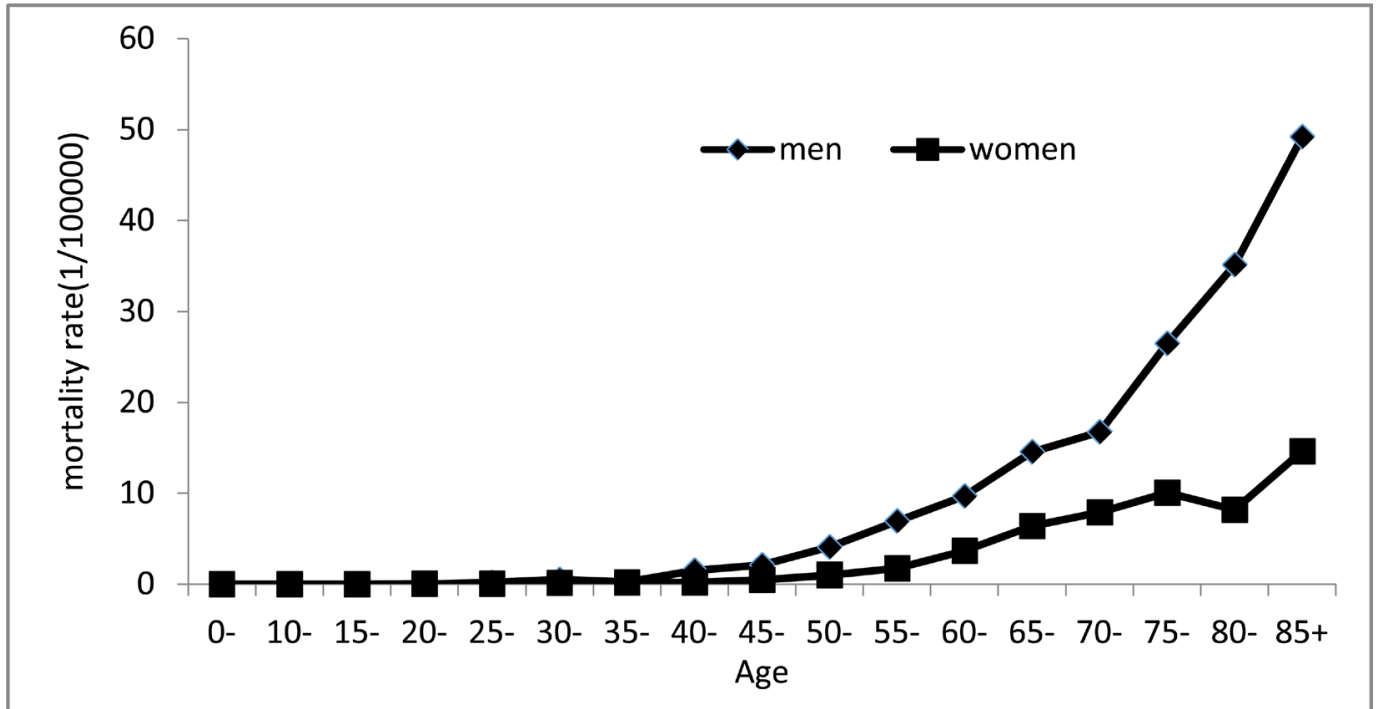

Figure 1. The gender-specific mortality rate of pancreatic cancer in Inner Mongolia, 2008-2014.

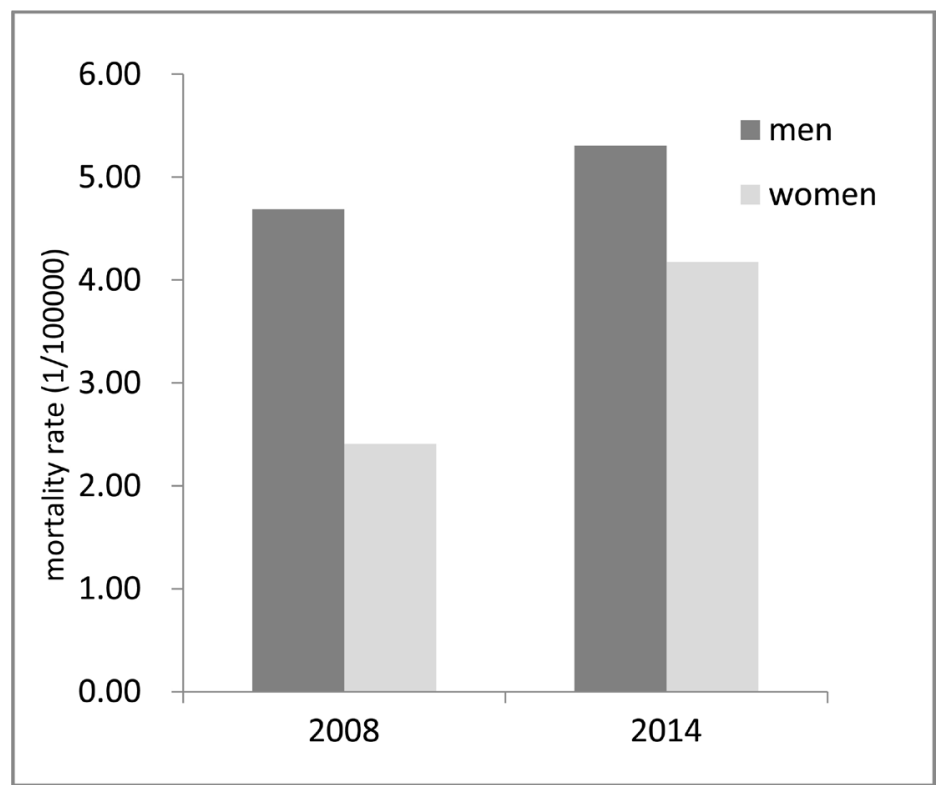

Figure 2. The gender-specific mortality rate of pancreatic cancer in Inner Mongolia in 2008 and 2014.

Table 1. AYLL, PYLL and PYLLR of pancreatic cancer in Inner Mongolia, 2008-2014.

\begin{tabular}{ccccccc}
\hline & \multicolumn{2}{c}{ AYLL(years) } & \multicolumn{2}{c}{ PYLL(person-years) } & \multicolumn{2}{c}{ PYLLR(\%) } \\
\cline { 2 - 7 } year & men & Women & men & women & men & women \\
\hline 2008 & 12.69 & 19.78 & 723.19 & 553.94 & 0.75 & 0.59 \\
2009 & 9.11 & 14.06 & 564.52 & 534.36 & 0.46 & 0.46 \\
2010 & 12.07 & 15.16 & 820.9 & 485.21 & 0.67 & 0.41 \\
2011 & 10.12 & 12.52 & 749.07 & 650.93 & 0.60 & 0.56 \\
2012 & 12.50 & 13.97 & 749.71 & 516.91 & 0.59 & 0.44 \\
2013 & 11.21 & 14.75 & 1536.43 & 1490.12 & 0.50 & 0.54 \\
2014 & 13.81 & 15.16 & 2291.94 & 1773.9 & 0.73 & 0.63 \\
\hline
\end{tabular}


Table 2. Logistic regression analysis of socio-demographic characteristics for pancreatic cancer death in Inner Mongolia from 2008 to 2014.

\begin{tabular}{cccc}
\hline charateristics & OR & $95 \%$ CL & P \\
\hline Region & & & 0.000 \\
Eastern & reference & & \\
Midwestern & 0.456 & $0.379-0.547$ & 0.002 \\
Ethnicity & & & \\
Han & reference & & \\
Mongolian & 1.269 & $0.880-1.830$ & 0.000 \\
Other & 2.909 & $1.555-5.443$ & \\
Occupation & & & \\
Yes & reference & & 0.000 \\
No & 2.089 & $1.652-2.640$ & \\
Education level & & & \\
low & reference & & \\
high & 1.386 & $1.184-1.622$ & \\
\hline
\end{tabular}

fluctuated from $0.46 / 1000$ to $0.67 / 1000$ during the years of 2009 to 2013 , more than $0.7 / 1000$ in 2008 and 2014. PYLLR in women was fluctuated from $0.41 / 1000$ to $0.63 / 1000$ during the years of 2008 to 2014 .

Table 2 shows logistic regression analysis of socio-demographic characteristic for pancreatic cancer death in Inner Mongolia from 2008 to 2014. The OR in midwestern region was 0.456 times than that in eastern. The OR in other ethnic groups was nearly 3 times than that in ethnic Han. The OR in the no occupation was 2 times than that in occupation. The OR in higher education level was 1.4 times compared with lower education level.

\section{Discussion}

The average mortality rate of pancreatic cancer $(4.42 / 100,000)$ in Inner Mongolia in 2008-2014 was lower than that in China with 6.61/100,000 in 2012 [5], but slightly higher than that in worldwide with 4.1/100,000 in 2012 [13]. The mortality rate of pancreatic cancer in men was higher than that in women no matter what ages, the result was consistent with most other studies [5] [13] [14]. Higher mortality of men may due to them having much unhealthy diet habits, such as excessive drinking [15] and smoking [16]. Tobacco smoking is the major recognized risk factor for pancreatic cancer, with a relative risk of approximately 2 for current smokers compared to never smokers [16]. It is suggested that the prevention of pancreatic cancer among men is important.

In the present study, the mortality rate of pancreatic cancer was obviously higher in over the age of 65 groups. Our result indicated that pancreatic cancer mortality rate was increasing with aging for both genders. The global temporal trends are increasing significantly with age increasing [3] [11]. More population 
had pancreatic cancer at the age of $60-65$ and the age of $70-80$ years were up to the peak [17]. The age factor is an aging phenomenon that alters some of the mechanisms in the body or pancreatic cells, which are eventual transformated cancer cells on the result of each specific change in the target cell accumulates over time [18].

AYLL was used to estimate the effect of pancreatic cancer on life expectancy. Both PYLL and AYLL reflect premature death, they give greater weight to diseases that result in younger deaths and less weight to those affecting the elderly [19]. Our study showed that women had a higher AYLL than that in men, though men had higher pancreatic cancer mortality rate. This result suggested that the burden of premature death due to pancreatic cancer was more serious in women in Inner Mongolia.

The high level of education was a risk factor for pancreatic cancer by Logistic regression analysis. Previous study was opposite to our result [20]. However, the high level of education was associated with a higher risk of cancer in our previous study [9]. No occupation was a risk factor for pancreatic cancer, but other studies had shown that people who feel tired after a day's work are also more likely to develop pancreatic cancer [21].

In our study, the mortality rate of pancreatic cancer in 2014 was higher than that in 2008, the results showed that pancreatic cancer has become severe in Inner Mongolia. Pancreatic cancer will occupy the second most common cause of cancer related death in the USA With the world population of growing rapidly and the increase of aging, by 2030 [3]. We should pay more attention in pancreatic cancer in order to reduce the burden of the cancer mortality in Inner Mongolia.

\section{Conclusions}

The findings of this study suggest that mortality rate of pancreatic cancer in men was higher than in women, however, average years of life lost for women was significantly higher than that for men in Inner Mongolia. People who were more than 65 years old had high death risk for pancreatic cancer. In addition, the difference of regions, culture may be an important factor on the impact of pancreatic cancer. Understanding the pancreatic cancer of development helps us to make correct prevention of the cancer.

The limitation of our present study is that there were many other sociodemographic characteristics that could affect the pancreatic cancer death, such as drinking, smoking, chronic disease, insurance. Unfortunately, we did not obtain these data.

\section{Acknowledgements}

The study was supported by the Natural Science Foundation of Inner Mongolia, China (grant No. 2016MS0828).

\section{References}

[1] Raimondi, S., Maisonneuve, P. and Lowenfels, A.B. (2009) Epidemiology of Pan- 
creatic Cancer: An Overview. Cancer Detection \& Prevention, 27, 87-93.

[2] Ferlay, J., Soerjomataram, I., Ervik, M., Dikshit, R., Eser, S., Mathers, C., et al. (2013) Cancer Incidence and Mortality Worldwide: IARC Cancer Base No. 11. Lyon, France: International Agency for Research on Cancer. http://globocan.iarc.fr/Default.aspx

[3] Rahib, L., Smith, B.D., Aizenberg, R., Rosenzweig, A.B., Fleshman, J.M. and Matrisian, L.M. (2014) Projecting Cancer Incidence and Deaths to 2030: The Unexpected Burden of Thyroid, Liver and Pancreas Cancer in the United States. Cancer Research, 74, 2913-2921. https://doi.org/10.1158/0008-5472.CAN-14-0155

[4] Lowenfels, A.B. and Maisonneuve, P. (2004) Epidemiology and Prevention of Pancreatic Cancer. Japanese Journal of Clinical Oncology, 34, 238-244.

https://doi.org/10.1093/jjco/hyh045

[5] Parkin, D.M., Bray, F., Ferlay, J. and Pisani, P. (2001) Estimating the World Cancer Burden: Globocan 2000. International Journal of Cancer, 94, 153-156. https://doi.org/10.1002/ijc.1440

[6] Seino, T., Nakadaira, H., Endoh, K. and Yamamoto, M. (2008) Changes in Pancreatic Cancer Mortality, Period Patterns, and Birth Cohort Patterns in Japan: Analysis of Mortality Data in the Period 1968-2002. Environmental Health and Preventive Medicine, 13, 234-242. https://doi.org/10.1007/s12199-008-0036-y

[7] Chen, W.Q., Liang, D., Zhang, S.W., Zheng, R.S. and He, Y.T. (2013) Pancreatic Cancer Incidence and Mortality Patterns in China, 2009. Asian Pacific Journal of Cancer Prevention, 14, 7321. https://doi.org/10.7314/APJCP.2013.14.12.7321

[8] Lin, Q. J., Feng, Y., Chen, J. and Fu, D.L. (2015) Current Status and Progress of Pancreatic Cancer in China. World Journal of Gastroenterology, 21, 7988-8003.

[9] Xin, K.P., Du, M.L., Li, Z.J., Li, Y., Li, W., Su, X., et al. (2014) Mortality of Urinary Tract Cancer in Inner Mongolia 2008-2012. Asian Pacific Journal of Cancer Prevention, 15, 2831-2834. https://doi.org/10.7314/APJCP.2014.15.6.2831

[10] Guo, W., Hao, W., Du, M., Su, Z., Hu, Y., Xia, Y., et al. (2015) Bone Cancer Mortality in Inner Mongolia from 2008 to 2012. Open Journal of Epidemiology, 5, 59-64. https://doi.org/10.4236/ojepi.2015.51008

[11] Chen, L., Du, M., Zhang, H., Xu, Y., Wang, Q., Zuo, F., et al. (2016) Anemia Related Mortality in Inner Mongolia in 2008-2012. Global Journal of Health Science, 9, 109. https://doi.org/10.5539/gjhs.v9n3p109

[12] Qing-Yun, L.U., Lan, S.Y., Chen, J.G., Zhu, J. and Zhang, Y.H. (2008) The Mortality of Malignant Tumors for the Residents in Qidong and Its Life Lost Analysis during 1986-2004. Jiangsu Journal of Preventive Medicine.

[13] Etxeberria, J., Goicoa, T., Lópezabente, G., Riebler, A. and Ugarte, M.D. (2017) Spatial Gender-Age-Period-Cohort Analysis of Pancreatic Cancer Mortality in Spain (1990-2013). Plos One, 12, e0169751. https://doi.org/10.1371/journal.pone.0169751

[14] Kuang, T.T., Jin, D.Y., Wang, D.S., Xu, X.F., Ni, X.L., Wu, W.C., et al. (2009) Clinical Epidemiological Analysis of the Relationship between Pancreatic Cancer and Diabetes Mellitus: Data from a Single Institution in China. Journal of Digestive Diseases, 10, 26-29. https://doi.org/10.1111/j.1751-2980.2008.00359.x

[15] Lu, P.Y., Shu, L., Shen, S.S., Chen, X.J. and Zhang, X.Y. (2017) Dietary Patterns and Pancreatic Cancer Risk: A Meta-Analysis. Nutrients, 9, 38. https://doi.org/10.3390/nu9010038

[16] Iodice, S., Gandini, S., Maisonneuve, P. and Lowenfels, A.B. (2008) Tobacco and the Risk of Pancreatic Cancer: A Review and Meta-Analysis. Langenbeck's Archives of Surgery, 393, 535-545. https://doi.org/10.1007/s00423-007-0266-2 
[17] Michaud, D.S. (2004) Epidemiology of Pancreatic Cancer. Minerva Chirurgica, 59, 99-111.

[18] Zhou, G.Z., Li, Z.S. and Zou, X.P. (2002) Research Progress on Etiology and Epidemiology of Pancreatic Cancer. China Journal of Cancer Prevention and Treatment, 9, 225-227.

[19] Pham, T.M., Fujino, Y.S. and Yoshimura, T. (2010) Premature Mortality Due to Cancer in Japan, 1995 and 2005. International Journal of Cancer, 127, 190-194. https://doi.org/10.1002/ijc.25021

[20] Hassan, M.M., Bondy, M.L., Wolff, R.A., Abbruzzese, J.L., Vauthey, J.N., Pisters, P.W., et al. (2007) Risk Factors for Pancreatic Cancer: Case-Control Study. American Journal of Gastroenterology, 102, 2696. https://doi.org/10.1111/j.1572-0241.2007.01510.x

[21] Nilsen, T.I.L. and Vatten, L.J. (2000) A Prospective Study of Lifestyle Factors and the Risk of Pancreatic Cancer in Nord-Trøndelag, Norway. Cancer Causes \& Control, 11, 645-652. https://doi.org/10.1023/A:1008916123357

Submit or recommend next manuscript to SCIRP and we will provide best service for you:

Accepting pre-submission inquiries through Email, Facebook, LinkedIn, Twitter, etc. A wide selection of journals (inclusive of 9 subjects, more than 200 journals)

Providing 24-hour high-quality service

User-friendly online submission system

Fair and swift peer-review system

Efficient typesetting and proofreading procedure

Display of the result of downloads and visits, as well as the number of cited articles

Maximum dissemination of your research work

Submit your manuscript at: http://papersubmission.scirp.org/

Or contact ojepi@scirp.org 